\title{
Managing data and complexity in energy systems
}

\author{
Friederich Kupzog ${ }^{1}$ - Wilfried Elmenreich ${ }^{2}$ - Ronald Bieber ${ }^{3}$
}

(C) Springer-Verlag Berlin Heidelberg 2016

A decade ago, pioneers across the world began to think of information and communication technologies as key contributors to the transition of our energy system to a network of sustainable low-carbon producers and consumers. This idea was dreamt up some time before, but with recent technological advances in terms of computing power, communication bandwidth and significant reduction in system costs, more and more approaches became feasible. The worlds of electrical engineering on one side and informatics/information and communication technologies on the other side had a new connection point, which was called "smart grid". In those days, strong day-to-day efforts were required to explain the motivation for smart grid research.

In subsequent years, the field experienced a strong push with rising interest from industry and even energy infrastructure operators. Many basic concepts such as demand response or voltage control became common sense. In addition, from the beginning on, the research field was well supported by research agendas throughout Europe, with policy makers demanding and happily adopting better clarity and common definitions.

Some years later, the field had developed from a set of early concepts to a spectrum of component and system solutions of much higher maturity. Many approaches were validated in the field in the frame of national and European research programs such as FP7, e-Energy in Germany or "Energiesysteme der Zukunft" in Austria. With this, a substantial research

Friederich Kupzog

friederich.kupzog@ait.ac.at

1 AIT Austrian Insitute of Technology GmbH, Wien, Austria

2 Alpen-Adria-Universität Klagenfurt, Klagenfurt am Wörthersee, Austria

3 Austrian Computer Society, Wien, Austria community had developed. It was time to identify the field of "Energy Informatics" as a full-grown research field.

Young researchers entering the field today will have very different experiences compared to the situation ten years ago. The available literature now exceeds by far what can be overseen by a single person. However, many concepts are clearly described now, taught in lectures and defined in books. It is no longer possible to compare innovative solutions to the old or "conventional" power system; applications of Energy Informatics have found their way into most aspects of design, planning and operation of power systems where required. The vision of a technological "smart grid" revolution has been replaced by the insight that there will be an incremental update of existing infrastructure with a large number of different innovative aspects applied to different parts of the system. Furthermore, with the D-A-CH + Energy Informatics conference series a researcher today has a good starting point to learn about important research challenges and to network with other researchers in the area.

The objective of D-A-CH + Energy Informatics 2016 is to further support this process of a research-based development and implementation phase of adequate information and communication technologies (ICT) and to foster the transfer between academia, industry, and service providers in the D-A-CH region Germany, Austria and Switzerland in close cooperation with other European partners. The conference addresses both scientists and practitioners.

The guiding topic of this issue is "Managing Data and Complexity in Energy Systems". A strong contribution from Informatics is required to handle the sharply growing complexity of energy systems with a large share of renewable energy sources and more and more dynamic operation paradigms. At the same time, it is mandatory to gain deeper insights into the behavior of the infrastructure and its users, taking into account the resulting challenges in privacy and 
data analysis. All submitted papers focus on this field and can be categorized into four main topics:

Energy networks-digitalization of electricity network infrastructure, integration of renewable energies, behavioral and forecast models for system users, modelling of future scenarios.

Mobility-coordinated charging management for e-cars and second use of batteries.

Buildings - optimization of the interaction between building management systems, HVAC and energy networks, innovative techniques for energy management.

Cross cutting-Privacy enhancing technologies, validation of networked smart grid systems, analysis of energy data, market modelling.

We would like to thank all authors who have submitted their work to the conference. Following the successful conferences in Oldenburg 2012, Vienna 2013, Zurich 2014 and Karlsruhe in 2015 respectively, 48 manuscripts have been submitted in 2016, whereof twenty revised versions have been included in this issue.

$\mathrm{D}-\mathrm{A}-\mathrm{CH}+$ Energy Informatics is a yearly event organized on joint initiative of Smart Grids D-A-CH-a cooperation of the German Federal Ministry for Economic Affairs and Energy, the Austrian Ministry for Transport, Innovation and Technology, and the Swiss Federal Office of Energy (see also http://www.smartgrids-dach.eu/).

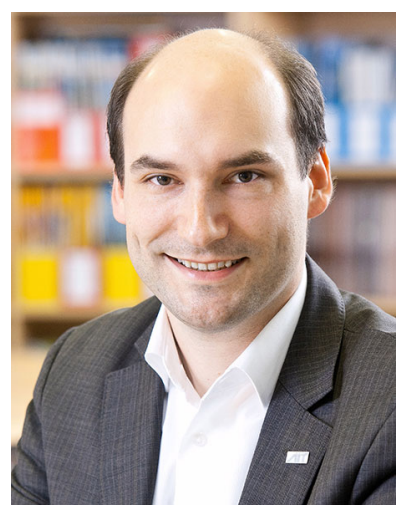

Friederich Kupzog achieved the Diploma Engineer degree of electrical engineering and information technology from RWTH Aachen. In 2006, he joined the Institute of Computer Technology at Vienna Technical University, Austria, where he achieved his PhD Degree in 2008. Until 2012, he stayed at the University as Post-Doc and managed the research group "Energy \& IT" at the Institute of Computer Technology. Since 2012, Dr. Kupzog is Senior Scientist at the AIT Austrian Institute of Technology GmbH. His research interest lies in verification methods for networked smart grid systems. He coordinates the thematic field "Smart Grids ICT \& Controls", managing research projects together with industry, power grid operators and other research partners.

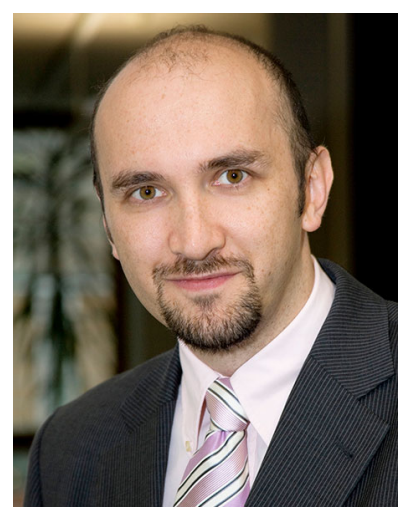

Wilfried Elmenreich is professor for Smart Grids at the Institute of Networked and Embedded Systems at the Alpen-AdriaUniversität Klagenfurt, Austria. $\mathrm{He}$ is also affiliated with the Lakeside Labs cluster in Klagenfurt, a research and innovation cluster on self-organizing networked systems. He studied computer science at the Vienna University of Technology, where he received his doctoral degree in 2002 with distinction. He was granted venia docendi in the field computer engineering from Vienna University of Technology in 2008. He was a visiting researcher at the Vanderbilt University in 2005 and at the CISTER/IPP-Hurray Research Unit at the Polytechnic Institute of Porto in 2007. In 2007 he moved to Alpen-Adria-Universität Klagenfurt as a senior researcher. In Winter term 2012-2013 he was acting professor for complex systems engineering at the University of Passau. Since April 2013, he holds a professorship for Smart Grids at Alpen-AdriaUniversität Klagenfurt. He is editor of 5 books and published over 150 papers in the field of networked and embedded systems. Elmenreich is senate member of Alpen-Adria-Universität Klagenfurt, Senior Member of IEEE and counselor of the Klagenfurt's IEEE student branch.

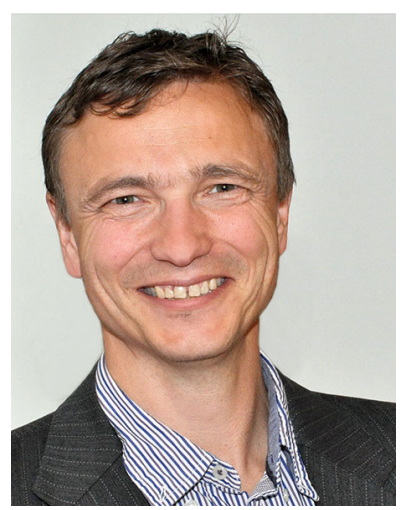

Ronald Bieber is Secretary General of the Austrian Computer Society since 2011. Before he was project manager (level B of IPMA as well as PMP) for several companies (Siemens, ATOS) in different fields of IT. Between 2003 and 2006 he was leading projects at the Austrian Institute of Technology (AIT) aiming to evaluate the security research in Austria in general as well as for the analysis of teh technology transfer at the universities of Vienna. From 2000 till 2003 Ronald managed the German contribution for an ESA satellite project (Herschel) at the university of Cologne, Germany. He did his PhD at one of the Joint Research Centers of the European Union in Belgium. Afterwards he worked for more than two years as Postdoc at the University of Groningen, The Netherlands, in the field of few body physics. 